\title{
BOUNDARY VALUE PROBLEMS FOR HILFER FRACTIONAL DIFFERENTIAL EQUATIONS WITH KATUGAMPOLA FRACTIONAL INTEGRAL AND ANTI-PERIODIC CONDITIONS
}

\author{
ABDELATIF BOUTIARA, MAAMAR BENBACHIR, and KADDOUR GUERBATI
}

\begin{abstract}
The purpose of this paper is to investigate the existence and uniqueness of solutions for a new class of nonlinear fractional differential equations involving Hilfer fractional operator with fractional integral boundary conditions. Our analysis relies on classical fixed point theorems and the Boyd-Wong nonlinear contraction. At the end, an illustrative example is presented. The boundary conditions introduced in this work are of quite general nature and can be reduce to many special cases by fixing the parameters involved in the conditions.
\end{abstract}

MSC 2010. Primary: 26A33. Secondary: 34B15.

Key words. Fractional differential equation, Hilfer fractional derivative, Katugampola fractional integral, fixed point theorems.

\section{REFERENCES}

[1] M.A. Abdo, H.A. Wahash and S.K. Panchat, Positive solutions of a fractional differential equation with integral boundary conditions, J. Appl. Math. Comput. Mech., 17 (2018), 5-15.

[2] R.P. Agarwal, M. Meehan and D. O'Regan, Fixed point theory and applications, Cambridge Tracts in Mathematics, Vol. 141, Cambridge University Press, 2001.

[3] B. Ahmad, S.K. Ntouyas, J. Tariboon and A. Alsaedi, Caputo Type fractional differential equations with nonlocal Riemann-Liouville and Erdélyi-Kober type integral boundary conditions, Filomat, 31 (2017), 4515-4529.

[4] B. Ahmad, S.K. Ntouyas and J. Tariboon, Nonlocal fractional-order boundary value problems with generalized Riemann-Liouville integral boundary conditions, Journal of Computational Analysis and Applications, 23 (2017), 1281-1296.

[5] A. Ahmadkhanlu, Existence and uniqueness results for a class of fractional differential equations with an integral fractional boundary condition, Filomat, 31 (2017), 1241-1249.

[6] M. Benchohra, S. Hamani and S.K. Ntouyas, Boundary value problems for differential equations with fractional order, Surv. Math. Appl., 3 (2008), 1-12.

[7] W. Benhamida, J.R. Graef and S. Hamani, Boundary value problems for fractional differential equations with integral and anti-periodic conditions in a Banach space, Progress in Fractional Differentiation and Applications, 4 (2018), 65-70.

[8] S.P. Bhairat, Existence and continuation of solutions of Hilfer fractional differential equations, J. Math. Model., 7 (2019), 1-20.

The authors thank the referee for his helpful comments and suggestions.

DOI: $10.24193 /$ mathcluj.2021.2.07 
[9] D.W. Boyd and J.S.W. Wong, On nonlinear contractions, Proc. Amer. Math. Soc., 20 (1969), 458-464.

[10] A. Boutiara, M. Benbachir and K. Guerbati, Caputo type fractional differential equation with Katugampola fractional integral conditions, in The 2nd International Conference on Mathematics and Information Technology (ICMIT), Adrar, Algeria, 2020, pp. 25-31.

[11] A. Boutiara, M. Benbachir and K. Guerbati, Caputo type fractional differential equation with nonlocal Erdélyi-Kober type integral boundary conditions in Banach spaces, Surv. Math. Appl., 15 (2020), 399-418.

[12] T. Chen and W. Liu, An anti-periodic boundary value problem for the fractional differential equations with a p-Laplacian operator, Appl. Math. Lett., 25 (2012), 1671-1675.

[13] R. Hilfer, Applications of fractional calculus in physics, World Scientific, Singapore, 2000.

[14] R. Hilfer, Threefold introduction to fractional derivatives, in Anomalous transport: foundations and applications, Wiley-VCH, Weinheim, 2008, 17-73.

[15] R. Hilfer, Y. Luchko and Z. Tomovski, Operational method for the solution of fractional differential equations with generalized Riemann-Lioville fractional derivative, Fract. Calc. Appl. Anal., 12 (2009), 289-318.

[16] R. Kamocki and C. Obcznnski, On fractional Cauchy-type problems containing Hilfer derivative, Electron. J. Qual. Theory Differ. Equ., 50 (2016), 1-12.

[17] U.N. Katugampola, New approach to a generalized fractional integral, Appl. Math. Comput., 218 (2011), 860-865.

[18] A.A. Kilbas, H.M. Srivastava and J.J. Trujillo, Theory and applications of fractional differential equations, North-Holland Mathematics Studies, Vol. 204, Elsevier, 2006.

[19] N.I. Mahmudov and S. Emin, Fractional-order boundary value problems with Katugampola fractional integral conditions, Adv. Difference Equ., 2018, Article 81, 1-17.

[20] K.S. Miller and B. Ross, An introduction to the fractional calculus and differential equations, John Wiley, New York, 1993.

[21] I. Podlubny, Fractional differential equations, Academic Press, New York, 1999.

[22] D.R. Smart, Fixed point theorems, Cambridge University Press, 1980.

[23] D. Vivek, K. Kanagarajan and E.M. Elsayed, Nonlocal initial value problems for implicit differential equations with Hilfer-Hadamard fractional derivative, Nonlinear Analysis: Modelling and Control, 23 (2018), 341-360.

[24] H. Zhang, Nonlocal boundary value problems of fractional order at resonance with integral conditions, Adv. Difference Equ., 2017, Article 326, 1-12.

[25] S. Zhang, The existence of a positive solution for a nonlinear fractional differential equation, Aust. J. Math. Anal. Appl., 252 (2000), 804-812.

Received November 25, 2019

Accepted April 25, 2020 
University of Ghardaia

Laboratory of Mathematics And Applied Sciences

Ghardaia, Algeria

E-mail: boutiara_a@yahoo.com

https://orcid.org/0000-0002-6032-4694

E-mail: guerbati_k@yahoo.com

https://orcid.org/0000-0003-4256-3760

University of Saad Dahlab

Faculty of Sciences

Blida 1, Algeria

E-mail: mbenbachir2001@gmail.com

https://orcid.org/0000-0003-3519-1153 